\title{
Evaluation of a Apo-1/Fas promoter polymorphism in Korean stroke patients
}

\author{
Jung-Chul Seo', Sang-Won Han', Chang-Sik \\ Yin $^{2}$, Hyung-Kyun Koh${ }^{2}$, Chang-Hwan Kim², Ee- \\ Hwa Kim ${ }^{3}$, Kang-Hyun Leem ${ }^{4}$, Hyang-Sook \\ Lee $^{5}$, Hi-Joon Park ${ }^{5}$, Soon-Ae Kim ${ }^{5}$, Bong-Keun \\ Choe $^{5}$, Hee-Jae Lee ${ }^{5}$, Sung-Vin Yim ${ }^{5}$, Chang-Ju \\ $\mathrm{Kim}^{5}$ and Joo-Ho Chung ${ }^{5,6}$ \\ ${ }^{1}$ Department of Acupuncture and Moxibustion, College of Oriental
Medicine, Kyungsan University, Gumi 730-090, Korea
${ }^{2}$ Kyung-Hee University, Seoul 130-701, Korea
${ }^{3}$ Se-Myung University, Jecheon 390-711, Korea
${ }^{4}$ College of Pharmacy, Woosuk University, Jeonjoo 565-701, Korea
${ }^{5}$ Kohwang Medical Research Institute, College of Medicine, Kyung-
Hee University, Seoul 130-701, Korea
${ }^{6}$ Corresponding author: Tel, +82-2-961-0281;
Fax, +82-2-968-0560; E-mail, acumox@ @hanmail.net
}

Accepted 23 August 2002

Abbreviation: RFLP. restriction fragment length polymorphism; CT, computed tomography; MRI, magnetic resonance imaging; $\mathrm{ICH}$, intracerebral hemorrhage; SAH, subarachnoid hemorrhage; OR, odds ratios; $\mathrm{Cl}$, confidence intervals; SpA, spondyloarthropathies; SLE, systemic lupus erythematosus; RA, rheumatoid arthritis

\begin{abstract}
Apoptosis has been implicated in the pathogenesis of neurodegenerative diseases such as stroke and Alzheimer's disease. Apo-1/Fas gene is one of the mediators of apoptosis in stroke. Mval polymorphism is the first polymorphic marker identified in the Apo-1/Fas gene promoter, which was typed by PCR and followed by Mval digestion and gel electrophoresis. DNA isolated from peripheral blood collected from 91 stroke patients and 103 healthy blood donors was used for genotypes of GG, GA and AA by sequence specific primer PCR. Mval polymorphism was examined based on Fas gene promotor region by restriction fragment length polymorphism (RFLP). The Fas-GG genotype was the least frequent in patients with stroke and healthy controls $(P=0.57)$. In normal Korean controls the Mval polymorphism GA, AA and GG were $48.6 \%$, $34.9 \%$ and $16.5 \%$. In stroke patients were $56.2 \%, 29.6 \%$ and $14.2 \%$ respectively. And the allelic frequencies of Mval*2 (G) allele were less frequent than Mval*1 (A) allele in patients with stroke and healthy controls $(P=0.76)$. In normal Korean controls $\left.M v a\right|^{\star} 1(A)$ and
\end{abstract}

Mval*2 (G) alleles were $59.2 \%$ and $\mathbf{4 0 . 8 \%}$. In stroke patients were $57.6 \%$ and $42.4 \%$, respectively. Our results, pending confirmation in a larger study, indicate that the Fas genotype may not appear to be a risk factor for stroke in Korean stroke patients.

Keywords: cerebrovascular accident, CD95 antigen, restriction fragment length polymorphism, promoter regions

\section{Introduction}

Apo-1/Fas, also known as CD95, is a transmembrane protein that mediates apoptosis (Nagata, 1994) and a member of the tumor necrosis factor/nerve growth factor (TNF/NGF) receptor superfamily, which transduces the apoptotic signal into susceptible target cells (Leithauser et al., 1993; Kim et al., 2000). Gene expression can be regulated by a number of genetic elements located in the $5^{1}$ upstream region of the gene. Variances in this upstream sequence can result in different level of gene expression. The genome organization of the Apo-1/Fas gene has been determined and the promoter region of the gene characterized (Cheng et al., 1995). The later encompasses a 2,000-bp sequence, which is subdivided into a basal promoter, enhancer and silencer region (Rudert et al., 1995). The recent identification of two polymorphisms on the $5^{\prime}$ flanking region on the human Apo-1/Fas gene has provided useful markers for the investigation of the genetic contribution of Apo-1/Fas gene (Huang et al., 1997). The Mval restriction length fragment polymorphism (RFLP), a polymorphic marker identified in the Apo-1/Fas gene, is located at -670 nucleotide within the enhancer region and results from a $\mathrm{GA} \rightarrow \mathrm{GG}$ substitution, which creates Mval restriction site. The polymorphism is situated on a consensus sequence of the gamma-activated sequence and thus may have a potential role in gene regulation (Cheng et al., 1995). To date, genetic polymorphism in the $5^{\prime}$ flanking region of the Apo-1/Fas gene has not been described in stroke. In this study, we investigated Mval polymorphism in the Apo-1/Fas promoter region in Korean stroke patients.

\section{Materials and Methods}

\section{Study population}

The control group consisted of 103 apparently healthy Korean and the mean age of these individuals was 57.1 
year (from 29 to 75). Controls were selected from healthy subjects who underwent the 2000 health examinations of Seoul City. The stroke patient group consisted of 91 Korean stroke patients and the mean age of patients was 59.5 year (from 28 to 76 ). Stroke subjects were selected from November 1, 2000, until December 31, 2001, who were admitted to the stroke service of the Department of Acupuncture and Moxibustion, College of Oriental Medicine, Kyung-Hee University, Seoul, Korea. Following baseline characteristics and vascular risk factors were recorded; age, gender, hypertension (treated or $>160 \mathrm{mmHg}$ systolic or $>90 \mathrm{mmHg}$ diastolic), diabetes mellitus (treated or fasting glucose $>110 \mathrm{mg} / \mathrm{dL}$ ). Of these pa-tients, 16 subjects were excluded from this study ( 1 was dead on arrival, 6 were transported to other hospitals, and 9 declined to give consent). Fas genotypes were undeterminable in an additional 4 subjects. Ultimately, 91 patients were enrolled in the current analysis.

\section{Definition and classification of stroke}

We included patients with neurological symptoms lasting $>24 \mathrm{~h}$ accompanied by corresponding focal density changes detected by brain computed tomography (CT) or magnetic resonance imaging (MRI), and excluded patients suffering from epidural (or subdural) hematoma, brain tumors, and accidental or iatrogenic stroke. Final diagnosis of stroke subtypes were confirmed by serial CT or MRI findings. Cerebral infarction was identified by gradual or sometimes rapid development of focal neurological symptoms and signs, such as hemiparesis, sensory impairment, and a low-density area in the CT image. Cerebral hemorrhage consists of intracerebral hemorrhage $(\mathrm{ICH})$ and subarachnoid hemorrhage (SAH). $\mathrm{ICH}$ was diagnosed when rapid evolution of focal neurological signs, quick progression into coma, signs of meningeal irritation, headache, and high-density areas in $\mathrm{CT}$ findings were observed. SAH was also diagnosed when such clinical observations as the sudden onset of severe headaches with a relatively momentary disturbance in consciousness, signs of meningeal irritation, absence of focal neurological signs, and presence of blood in the cerebrospinal fluid or the subarachnoidal space was indicated by high-density regions on CT images.

\section{Blood sample collection}

Venous blood samples from controls were obtained without regard to the time of the last meal. In subjects with stroke, blood samples were obtained within $24 \mathrm{~h}$ of stroke onset. These study were approved by the ethics review committee of the Medical Research Institute, Medical Center. Informed consent was obtained from all subjects. If patients were incommunicative, it was obtained from close relatives.

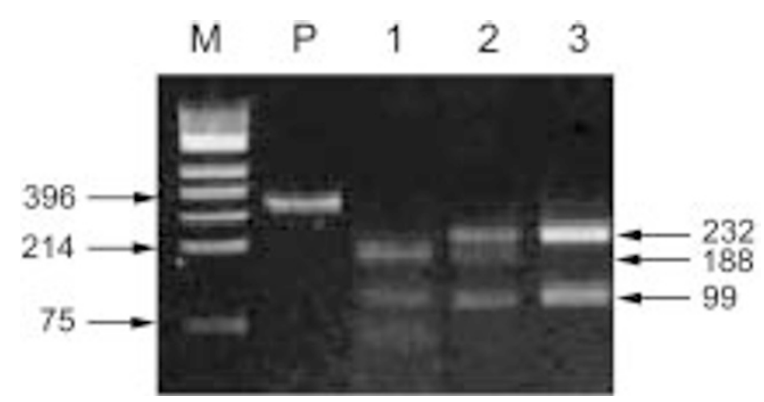

Figure 1. Mva I polymorphism in Apo-1/Fas gene. The PCR products were digested with Mval and subjected to electorophoresis in a 3\% agarose gel, followed by ethidium bromide staining. Lane $M$, size marker; Lane $P$, undigested PCR product; Lane 1, homozygous Mval*2 (G/G) genotype; Lane 2, heterozygous Mval (G/A) genotype; Lane 3, homozygous Mval ${ }^{*} 1$ (A/A) genotype.

\section{DNA preparation and genotyping}

Blood samples for DNA extraction from all subjects were collected in EDTA tube. Genomic DNA was extracted using DNA isolation kit for mammalian blood (Boehringer Mannheim, Indianapolis, IN). The Mval RFLP was studied by PCR amplification followed by Mval restriction enzyme digestion. The Fas gene was amplified using a Perkin Elmer GeneAmp PCR system 9600 (Roche Diagnostic Systems). The primers, which were published (Huang et al., 1997), were 5'-CTACCTAAGAGCTATCTACCG TTC-3' and 5'-GGCTGTCCATGTTGTGGCTGC-3'. The reaction profiles were as follows; denaturation at $94^{\circ} \mathrm{C}$ for $30 \mathrm{~s}$, annealing at $58^{\circ} \mathrm{C}$ for $1 \mathrm{~min}$, extension at $72^{\circ} \mathrm{C}$ for $1 \mathrm{~min}$, for 40 cycles. The cycling was preceded by a single 5 min denaturation at $94^{\circ} \mathrm{C}$, and followed by a single cycle of extension at $72^{\circ} \mathrm{C}$ for $10 \mathrm{~min}$. All PCR products were confirmed by loading $1.5 \%$ agarose gel electrophoresis, $10 \mu \mathrm{l}$ of reaction mixture from each sample were digested with Mval restriction enzyme under recommended conditions (Boehringer Mannheim, Indianapolis, IN). These products were loaded onto a $3 \%$ agarose gels in $0.5 \times$ TBE running buffer. Two polymorphic alleles, allele Mval*1 (A: $232 \mathrm{bp}$ ) and allele Mval*2 (G: $188 \mathrm{bp}$ ), were produced depending on the

Table 1. Clinical characteristics of stroke patients and controls. $\chi^{2}$ test was used to compare values of stroke patients and controls for all parameters except for age, which was compared by Student's $t$ test.

\begin{tabular}{lccc}
\hline & $\begin{array}{c}\text { Controls } \\
(\mathrm{n}=103)\end{array}$ & $\begin{array}{c}\text { Stroke } \\
\text { patients } \\
(\mathrm{n}=91)\end{array}$ & $P$ value \\
\hline Male (\%) & $37(35.9)$ & $40(43.9)$ & 0.25 \\
Age, mean \pm SD, year & $57.1 \pm 9.16$ & $59.5 \pm 8.53$ & 0.06 \\
Cerebral Infarction (\%) & 0 & $74(81.3)$ & 0.00 \\
Cerebral Hemorrhage (\%) & 0 & $17(18.7)$ & 0.00 \\
Hypertension (\%) & 0 & $54(52.4)$ & 0.00 \\
Diabetes Mellitus (\%) & 0 & $38(36.8)$ & 0.00 \\
\hline
\end{tabular}


Table 2. Genotype and allele frequencies of polymorphism in Fas gene in stroke patients and controls. $\chi^{2}$ tests were used to compare genotype and allele frequencies between controls and all stroke patients and between controls and individual groups of stroke patients.

\begin{tabular}{|c|c|c|c|c|c|c|c|c|c|}
\hline & \multicolumn{4}{|c|}{ Genotype(\%) } & \multicolumn{5}{|c|}{ Allele frequency(\%) } \\
\hline & GA & GG & AA & $\begin{array}{c}P \\
\text { value }\end{array}$ & $G$ & A & $\begin{array}{c}P \\
\text { value }\end{array}$ & $\begin{array}{l}\text { Odds } \\
\text { ratio }\end{array}$ & $\begin{array}{l}\text { 95\% confidence } \\
\text { interval }\end{array}$ \\
\hline Controls & 48.6 & 16.5 & 34.9 & $\cdots$ & 40.8 & 59.2 & $\ldots$ & & \\
\hline All stroke patients & 56.2 & 14.2 & 29.6 & 0.57 & 42.4 & 57.6 & 0.76 & 0.93 & $0.62-1.40$ \\
\hline Cerebral infarction & 55.5 & 13.5 & 31.0 & 0.65 & 41.3 & 58.7 & 0.93 & 0.98 & $0.63-1.50$ \\
\hline Cerebral hemorrhage & 58.9 & 17.6 & 23.5 & 0.64 & 47.1 & 52.9 & 0.49 & 0.77 & $0.37-1.60$ \\
\hline Hypertension & 57.5 & 12.9 & 29.6 & 0.56 & 41.7 & 58.3 & 0.87 & 0.96 & $0.60-1.54$ \\
\hline Diabetes mellitus & 60.6 & 10.5 & 28.9 & 0.41 & 40.8 & 59.2 & 0.99 & 0.99 & $0.58-1.70$ \\
\hline
\end{tabular}

presence of $A$ or $G$ allele at the -670 position (Figure 1).

\section{Statistical analysis}

To compare the distribution of the Mval genotypes and the frequency of $M v a{ }^{*}{ }^{*}$ and $M v a{ }^{\star} 2$ alleles between Korean stroke patients and controls, $\chi^{2}$ tests was used. The odds ratios (OR) and 95\% confidence intervals (Cl) were used to quantify the association with stroke. The SAS statistical package (release 6.12, SAS Institute Inc) was used.

\section{Results}

Clinical characteristics of stroke patients and controls are shown in Table 1. Genotypic distributions and allelic frequencies of Mval polymorphism in normal Korean controls and related Korean stroke patients group are shown in Table 2. The Mval RFLP was examined in 91 stroke patients. The heterozygous form of Mval polymorphism (G/A) was $56.2 \%$ of stroke patients, while those homozygous forms for $M_{v a l}{ }^{*} 1$ form (A/A) and $M v a{ }^{*} 2$ form (G/G) were $29.6 \%$ and $14.2 \%$, respectively. On the other hand in 103 Korean healthy controls, the heterozygous form of Mval polymorphism (G/A) was noted in $48.6 \%$ of the normal population, while $M v a l^{\star} 1$ homozygous form (A/A) and Mval ${ }^{*} 2$ homozygous form $(G / G)$ were $34.9 \%$ and $16.5 \%$, respectively. There was no significant genotypic distribution difference between control and stroke group $(P=0.57)$. In stroke patients the frequency of $M v v^{*} 1$ and $M v a l^{*} 2$ alleles were $57.6 \%$ and $42.4 \%$, respectively. On the other hand in healthy controls the frequency of $M v a^{*}{ }^{*} 1$ and $M v a{ }^{*} 2$ alleles were $59.2 \%$ and $40.8 \%$, respectively. There was no significant allelic frequency difference between control and stroke group $(P=0.76)$. In case of cerebral infarction, cerebral hemorrhage, hypertension and diabetes mellitus there was no significant genotype $(P=0.65,0.64,0.56,0.41$, respectively) or allelic frequency $(P=0.93,0.49,0.87,0.99$, respectively) difference between control and stroke group.

\section{Discussion}

Apoptosis is a genetically controlled programmed cell death mechanism serving homeostatic functions (Cha et al., 2001), important to direct the development, and plays a critical role in neurodevelopment (Harrison, 1997). It is involved in the pathogenesis and pathophysiology of several known human diseases, such as autoimmune dysfunction, cancer, stroke and neurodegenerative diseases. In neurodegenerative changes, specific neurons under apoptotic cell death characterized by DNA fragmentation, increased levels of pro-apoptotic genes and apoptotic proteins (Offen et al., 2000). Stroke is a cli-nical concept of neurological disorder characterized by an acute faint, unconsciousness, excessive phlegm, hemi-paralysis, dysphasia, facial palsy and motor disorder, etc. Stroke develops several complications, among which sequela of stroke like motor disorder affects the family as well as the patient with great psychological and financial stress. Stroke is the second most fatal disease following cancer in Korea. Apo-1/Fas (CD95) gene up-regulation precedes apoptosis in many cell types and a potential role in apoptosis of neural and glial cells has already been investigated in many neurodegenerative disorders, such as Alzheimers disease, Parkinsons disease and Down syndrome (DelaMonte et al., 1997, 1998; Seidl et al., 1999).

Recently many polymorphism in stroke were investigated and some polymorphism such as $\alpha_{1}$-antichymotrypsin gene was found to be associated (Nicolas et al., 2000) but some polymorphism such as promoter of lipopolysaccharide receptor CD14 was not related (Daisuke et al., 2000). In Korean stroke patients chronic Helicobacter pylori infections might be a risk factor for ischemic cerebrovascular disease (Park et al., 2001). However, the polymorphism of the CD14 receptor was not associated with an increased risk for ischemic cerebrovascular disease (Park et al., 2001). And there was no significant associations between the angiotensinogen 235T alleles and hypertension or ischemic stroke (Jea et al., 2001). But the deletion 
polymorphism in the angiotensin-converting enzyme gene (ACE DD genotype) was more common in patients with ischemic stroke compared with the controls (Choi et al., 2000).

Fas promoter gene polymorphism study was carried out in Korean spondyloarthropathies (SpA), systemic lupus erythematosus (SLE) and rheumatoid arthritis (RA) patients (Lee et al., 2001). The Fas polymorphism was found to be associated with development of antiRNP antibodies in SLE. But there were no significant differences in the genotype and allele frequencies of the Fas promoter genes among SpA and RA (Lee et al., 2001). On the other hands, in Caucasian RA and SLE patients, the role of the Fas gene promoter Mval polymorphism was unclear (Huang et al., 1999). These findings suggest that there is ethnic difference in singlenucleotide polymorphism.

There are two major stroke types: cerebral infarction and hemorrhage. This is the first report showing the Fas gene polymorphisms with stroke including subtypes (infarction or hemorrhage) by use of CT or MRI findings in Korea. In this study we divided the stroke patients into two subgroups to investigate a possible association between the subgroups in Fas genotypes. But the results showed no association between the stroke subgroups. Among many known stroke risk factors such as hypertension, diabetes mellitus, cigarette smoking, heavy alcohol consumption etc., hypertension and diabetes mellitus are considered as greater risk factors. Investigation of a possible Fas genotypic association in stroke patients with hypertension or diabetes mellitus showed no association. The findings of this study need to be confirmed in a larger number of patient sizes. Additional experimental survey of the relationship between Fas and lifestyles with regard to stroke risk factor should be considered in the prevention of stroke through the promotion of more suitable lifestyles.

\section{Acknowledgments}

This work was supported by grants from the research project on Kim's ILCHIM Scholarship.

\section{References}

Cha YJ, Kim HS, Rhim H, Kim BE, Jeong SW, Kim IK. Activation of caspase-8 in 3-deazaadenosine-induced apoptosis of U-937 cells occurs downstream of caspase- 3 and caspase-9 without Fas receptor-ligand interaction. Exp Mol Med 2001;33:284-92

Cheng J, Liu C, Koopman WJ, Mountz JD. Characterization of human Fas gene. exon/intron organization and promoter region. J Immunol 1995;154:1239-45

Choi Y, Choi J, Han J, Park MK, Park K, Lee DH. An deletion/ insertion polymorphism of the angiotensin converting enzyme gene in ischemic stroke patients. J Korean Neurol Assoc 2000;18:261-6

Daisuke I, Mitsuru M, Norio T, Hideki S, Akira S, Ikuo S, Kiyoaki W, Yasuo F. Polymorphism in the promoter of lipopolysaccharide receptor CD14 and ischemic cerebrovascular disease. Stroke 2000;31:2661-4

DelaMonte SM, Sohn YK, Ganju N, Wands JR. p53- and CD95-associated apoptosis in neurodegenerative diseases. Lab Invest 1998;78:401-11

DelaMonte SM, Sohn YK, Wands JR. Correlates of p53- and Fas (CD95)-mediated apoptosis in Alzheimers disease. J Neurol Sci 1997;152:73-83

Harrison PJ. Schizophrenia: a disorder of neurodevelopment? Curr Opin Neurobiol 1997;7:285-9

Huang QR, Danis V, Lassere M, Edmonds J, Manolios N. Evalulation of a new Apo-1/Fas promoter polymorphism in rhuemtoid arthritis and systemic lupus erythematosus patients. Rhematology(Oxford) 1999;38:645-51

Huang QR, Morris D, Manolios N. Identification and characterization of polymorphisms in the promoter region of the human Apo-1/Fas (CD95) gene. Mol Immunol 1997;34:577-82

Jea JS, Bang CO, Lee TK, Park HK, Ahn MY, Hong SY. Lack of association between angiotensinogen M235T gene polymorphism and ischemic stroke in Korean. J Korean Neurol Assoc 2001;19:24-8

Kim KM, Lee K, Hong YS, Park HY. Fas-mediated apoptosis and expression of related genes in human malignant hematopoietic cells. Exp Mol Med 2000;32:246-54

Lee YH, Ji JD, Sohn J, Song GG. Polymorphsims of CTLA-4 exon $1+49$, CTLA-4 promoter -318 and Fas promoter -670 in spondyloarthropathies. Clin Rheumatol 2001;20:420-2

Lee YH, Kim YR, Ji JD, Sohn J, Song GG. Fas promoter -670 polymorphism is associated with development of anti-RNP antibodies in systemic lupus erythematosus. J Rheumatol 2001;28:2008-11

Leithauser F, Dhein J, Mechtersheimer G, Koretz K, Bruderlein S, Henne C, Schmidt A, Debatin KM, Krammer PH, Moller P. Constitutive and induced expression of Apo-1, a new member of the nerve growth factor/tumor necrosis factor receptor superfamily, in normal and neoplastic cells. Lab Invest 1993;69:415-29

Nagata S. Apoptosis regulated by a death factor and its receptor: Fas ligand and Fas. Philos Trans R Soc Lond B Biol Sci 1994;354:281-7

Nicolas V, Victor O, Marian R, Rafael O, Angel C. á1Antichymotrypsin gene polymorphism in patients with stroke. Stroke 2000;31:2103-5

Offen D, Elkon H, Melamed E. Apoptosis as a general cell death pathway in neurodegenerative diseases. I Neural Transm Suppl 2000;58:153-66

Park MH, Lee SH, Kim BJ, Park KW, Lee DH, Park MK. Helicobacter pylori infection and monocyte CD14 receptor 
gene polymorphism in stroke patients. J Korean Neurol Assoc 2001;19:337-41

Rudert F, Visser E, Forbes L, Lindridge E, Wang Y, Watson J. Identification of a silencer, enhancer, and basal promoter region in the human CD95 (Fas/Apo-1) gene. DNA Cell Biol
$1995 ; 14: 931-7$

Seidl R, Fang-Kircher S, Bidmon B, Cairns N, Nubec G. Apoptosis-associated proteins p53 and Apo-1/Fas (CD95) in brains of adult patients with Down syndrome. Neurosci Lett 1999;260:9-12 